\title{
Opportunistic pulmonary strongyloidiasis complicating asthma treated with steroids
}

\author{
T. W. HIGENBOT TAM a nd B. E. HEARD \\ Cardiothoracic Institute, at the London Chest Hospital, London E2 \\ and Brompton Hospital, London SW3
}

\begin{abstract}
Higenbottam, T. W. and Heard, B. E. (1976). Thorax, 31, 226-233. Opportunistic pulmonary strongyloidiasis complicating asthma treated with steroids. A man aged 57 years who had lived most of his life in London, suffered from asthma which had begun during army service in Burma 37 years previously. Latterly he was treated with increasing doses of corticosteroids but his symptoms continued to worsen and he died of asthma. Necropsy revealed a heavy opportunistic infection of the bronchi and lungs by the nematode Strongyloides stercoralis which he had presumably acquired while on service abroad.

The case illustrates the need, even in non-endemic areas, to suspect opportunistic pulmonary strongyloidiasis when a patient's asthma worsens despite treatment with increasing doses of corticosteroids. Although it is a potentially lethal iatrogenic opportunistic infection, it is amenable to treatment with anthelminthic agents if recognized in time.
\end{abstract}

The nematode worm Strongyloides stercoralis has a worldwide distribution but is most common in regions where the climate is warm and moist (Craig, Russell, and Jung, 1970). Sporadic cases reported from cool climates may have resulted from infection acquired abroad, although the infection may occasionally be acquired as a result of overcrowding and unsanitary conditions (MarcialRojas, 1971).

$S$. stercoralis is a nematode worm which causes a light to moderate infection of the bowel, producing an asymptomatic eosinophilia or mild gastrointestinal symptoms. It may persist many years after the host has left an endemic area (Corrigan, 1949; Brown and Perna, 1958; Wilson and Thompson, 1964; Cookson et al., 1972) by a process termed internal auto-infection (Craig et al., 1970).

Respiratory symptoms may occur during the migration of the infective filariform larvae through the lungs, either shortly after the initial infection, or subsequently due to episodes of autoinfection. The lungs are commonly involved in fatal cases of overwhelming strongyloidiasis (Andrade and Gomes, 1964; Bras et al., 1964). The worm has been found also in the lungs of patients dying from other respiratory disease (Chodkowska and Piekarniak, 1968; Woźniewskı, 1968; Seabury, Abadie, and Savoy, 1971).

In the present paper we report a case from the United Kingdom of fatal pulmonary strongyloidiasis in an asthmatic subject treated with corticosteroids. He had travelled abroad only once, $\frac{O}{\widetilde{N}}$ visiting Burma 37 years previously. The diagnosis was made at necropsy.

\section{CASE REPORT}

A 57-year-old Englishman had been subject to ? attacks of asthma for 37 years, first experienced $\frac{D}{2}$ when he was in Burma, and as a result of which he was invalided out of the army. There was no fr history of respiratory disease before that, nor was $N$ there any personal or family history of atopic N disorders.

For eight years before the final illness his activity had been limited by exertional dyspnoea $\frac{0}{\Phi}$ and he was treated in hospital on three occasions $\stackrel{\rho}{\rightarrow}$ for severe asthma. On the first of these in 1966, an eosinophilia of $1800 / \mathrm{mm}^{3}$ (total white cello

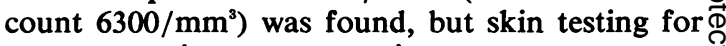
common antigens was negative.

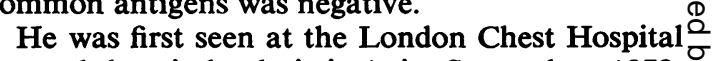
(second hospital admission) in September 1972, 
having received oral prednisone for six months. His chief symptom was severe exertional dyspnoea limiting walking on the flat to 3 minutes. On examination his respiratory rate was 22 per minute at rest, with marked inspiratory and expiratory wheezes. Gas analyses of arterial blood showed $\mathrm{PaO}_{2} 11.9 \mathrm{kPa}(90 \mathrm{mmHg}), \mathrm{PaCO}_{2} 2.66 \mathrm{kPa}(20$ $\mathrm{mmHg}$ ), and $\mathrm{pH} 7.5$ (breathing air). The peak expiratory flow was less than $90 \mathrm{l} / \mathrm{min}$ (predicted $455 \mathrm{l} / \mathrm{min}$ ) and the vital capacity (VC) and forced expired volume in one second $\left(F E V_{1}\right)$ were markedly reduced (see Fig. 1). The haemoglobin was $14.8 \mathrm{~g} / \mathrm{dl}$, the white cells were $9400 / \mathrm{mm}^{3}$, and the eosinophils were $11 / \mathrm{mm}^{3}$. Chest radiographs showed a large lung volume and a left-sided calcified pleural plaque. Sputum examination revealed no pathogenic organisms in smears or on culture. A course of increased dosage of oral prednisone, 7.5-30 mg per day over two weeks, reduced the dyspnoea and increased the VC and $\mathrm{FEV}_{1}$ (see Fig. 1). He received no antibiotics.

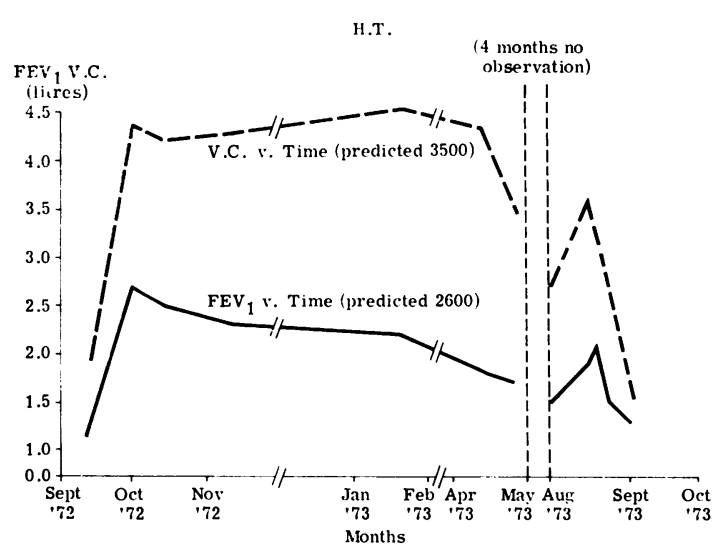

FIG. 1. A graph showing the forced expiratory volume in one second and vital capacity during the attendance at the London Chest Hospital.

For the next four months he remained well excert for one episode of increased dyspnoea, which responded to higher doses of oral prednisone for one week.

The last four months before his final admission in August 1973 were marked by progressively increasing exertional dyspnoea, in spite of increased doses of oral prednisone, up to $45 \mathrm{mg}$ per day. On admission his chief symptom was severe dyspnoea at rest, and examination revealed a respiratory rate of $30 / \mathrm{min}$ and bilateral inspiratory and expiratory wheezes. There was no pyrexia. Arterial blood gas analyses showed $\mathrm{PaO}_{2} 11 \cdot 3 \mathrm{kPa}(85$
$\mathrm{mmHg}$ ), $\mathrm{PaCO}_{2} 4.92 \mathrm{kPa}(37 \mathrm{mmHg}$ ), and $\mathrm{pH} 7.49$ (breathing air). The peak expiratory flow rate was $90 \mathrm{l} / \mathrm{min}$, increasing to $120 \mathrm{l} / \mathrm{min}$ after treatment with salbutamol aerosol and intermittent positive pressure breathing. The $\mathrm{FEV}_{1}$ and VC were reduced below the normal range (see Fig. 1). The haemoglobin was $13.5 \mathrm{~g} / \mathrm{dl}$. There was a neutrophil leucocytosis with a white cell count of $13000 i$ $\mathrm{mm}^{3}$ and $94 \%$ neutrophils. Only 2 eosinophils were seen per cubic millimetre. There was no change from earlier films on chest radiography and the sputum revealed no pathogens on culture.

On treatment with parenteral hydrocortisone, initially $1 \mathrm{~g}$ per day, together with ampicillin, $1 \mathrm{~g}$ per day, he initially improved (see Fig. 1). The hydrocortisone was reduced to $400 \mathrm{mg}$ per day parenterally. Efforts to replace it by oral steroid therapy in the form of equivalent doses of prednisolone, betamethasone, and prednisone were unsuccessful and failed to control his breathlessness; there was a reduction of peak flow values. The ampicillin was discontinued after seven days due to the development of an urticarial rash, which then quickly resolved.

Fourteen days after admission to hospital the patient's condition was progressively deteriorating, beginning with production of green sputum and with an episode of abdominal cramps and diarrhoea. The blood count revealed a neutrophil leucocytosis, total white count $13800 / \mathrm{mm}^{3}, 98 \%$ neutrophils, eosinophils only $20 / \mathrm{mm}^{3}$. Culture of sputum and stool revealed Klebsiella sp but blood cultures on three occasions were negative. The chest radiograph showed no changes.

Controlled fluid replacement, increased parenteral hydrocortisone administration, and antibiotic treatment, including gentamycin followed by cephalothin, failed to prevent worsening of his condition. The VC and $\mathrm{FEV}_{1}$ (see Fig. 1) three days before death were very low, and arterial blood gas analysis showed a $\mathrm{PaO}_{2} 8.37 \mathrm{kPa}$ (63 $\mathrm{mmHg}$ ), $\mathbf{P a C O}_{2} 3.45 \mathrm{kPa}(26 \mathrm{mmHg}$ ), and $\mathrm{pH} 7.44$ (breathing air). At this stage intermittent positive pressure breathing was commenced via an endotracheal tube, but he developed clinical evidence suggestive of pneumonia and then hypotension and uraemia. Death occurred in unresponsive cardiac asystole.

Further information was later available. This included a negative filarial complement fixation test and normal total IgE level. Both investigations were initiated early in the final illness.

PATHology At necropsy, externally there was a purpuric rash over the abdomen, and the con- 
junctivae were slightly icteric. Internally, the right pleural sac was obliterated completely by dense fibrous adhesions and the left pleural sac contained scattered adhesions and a trace of fluid. There were several large, nodular, fibrous, and calcified pleural plaques on the parietal pleura on both sides, lying laterally, posteriorly, and over the diaphragm. The pericardium and peritoneum appeared normal with minimal fluid present.

The heart weighed $475 \mathrm{~g}$. The right atrium was normal. The tricuspid valve was dilated to 140 $\mathrm{mm}$ in circumference (normal maximum $130 \mathrm{~mm}$ ) but the cusps were normal. The left atrium was normal, and the mitral valve was normal, circumference $105 \mathrm{~mm}$. The chamber of the left ventricle appeared larger than normal, but the wall was normal in thickness, measuring $15 \mathrm{~mm}$. The aortic valve was slightly dilated to $90 \mathrm{~mm}$ in circumference (normal maximum $80 \mathrm{~mm}$ ) but the cusps were normal. The coronary arteries were widely patent and showed only a trace of atherosclerosis. The aorta showed moderate atherosclerosis in the abdominal part. The renal arteries appeared normal. There were no emboli in the pulmonary trunk or pulmonary arteries and no thrombi were found in the iliac or femoral veins.

The larynx and trachea were normal. The left lung was increased threefold in weight to $1200 \mathrm{~g}$, and on the cut surface some of the medium-sized and small bronchi contained pale plugs of mucus. Some bronchi appeared inflamed and contained pus, and the parenchyma showed oedema of most of the lower lobe and parts of the upper lobe. There were many small foci of destructive centrilobular emphysema in the upper half of the lungs, and a few smaller foci in the lower half. There was no panlobular emphysema, no fibrosis to suggest asbestosis, and no evidence of embolism. The emphysema affected $20 \%$ of the area of the whole lung slice (Heard, 1969). The right lung was also increased threefold in weight to $1220 \mathrm{~g}$. The patterns of emphysema and oedema were similar to those observed in the left lung. In the apical segment there was an old stellate scar, presumed to be tuberculous.

The tongue, pharynx, oesophagus, stomach, duodenum, small and large intestines, appendix, and rectum appeared normal to the naked eye. Intestinal parasites were not suspected or sought at that time. The liver was normal in appearance and weighed $1750 \mathrm{~g}$. The gall bladder was normal and the bile ducts were patent. The pancreas was normal.

No abnormalities were detected in the thyroid or pituitary glands. The left adrenal gland ap- peared normal but the right was slightly reduced $\underset{\vec{s}}{\vec{*}}$ in size.

The spleen $(160 \mathrm{~g})$ was normal and also the lymph nodes and bone marrow. The left kidney weighed $210 \mathrm{~g}$, and the right $190 \mathrm{~g}$, and the cap- $\vec{\sigma}$ sules of both stripped easily to reveal smooth 0 surfaces; the cut surfaces showed slight pallor andis swelling of the cortices. The ureters, bladder, $\vec{\circ}$ prostate, and testes were normal.

The brain weighed $1350 \mathrm{~g}$ and appeared normal, $\vec{\omega}$ as did the meninges and vessels. The skeletal system appeared normal.

HISTOLOGICAL FINDINGS Sections taken throughin bronchi of all sizes and from all parts of both $N$ lungs showed larvae of $S$. stercoralis. The larvae were present in the bronchial lumen, the mucosa,, the ducts and acini of bronchial mucous glands, $\vec{\overrightarrow{ }}$ and the connective tissue around bronchi ando vessels (where they lay in the tissue spaces or in lymphatics (Fig. 2)) and also free in the alveolar $\overrightarrow{0}$ lumen (Fig. 3). The small bronchi and bronchiolesơ contained mucus, inflammatory cells which wereo mostly neutrophils, and also some red cells. The walls of bronchi and bronchioles were infiltrated금 by chronic inflammatory cells, consisting of manyo plasma cells and a small number of lymphocytesब and eosinophils (Fig. 4). There were many bacteria present, some probably having multiplied aftero death. Around the larvae within alveoli there were sometimes histiocytes with one or more nuclei, but usually there was no reaction.

The parasites were mostly in the form of larvae, but occasionally adult female worms were found histologically in or on the mucosa of small bronchi or bronchioles (Fig. 5). There were larvae in the parabronchial lymph node, and one of themi showed the head region with a long oesophagus 3 identifying it as a filariform larva (Fig. 6). It iso probable, however, that some of the larvae would? be rhabditiform (with a short oesophagus) becauseo in the cycle they are the precursors of filariform larvae by a process involving moulting. No eggsor were seen in the bronchi or lungs. The larvaen measured about 8 to $10 \mu$ in diameter, and in oblique section the greatest incomplete length ${ }_{0}^{\omega}$ sampled was about 50-100 $\mu$. Whole larvae are known to measure 14-16 $\mu$ in width, by 200-300 $\mu$ 宁 in length, but in sections they are usually incomes? pletely sampled and histological processing causes shrinkage. No parasites at all were found in $\mathrm{sec}^{-0}$ tions of the adrenals, spleen, liver or kidneys.

The bowel was not sampled at necropsy, but i is likely from previous reports that sections would have shown eggs and larvae in the crypts of the 


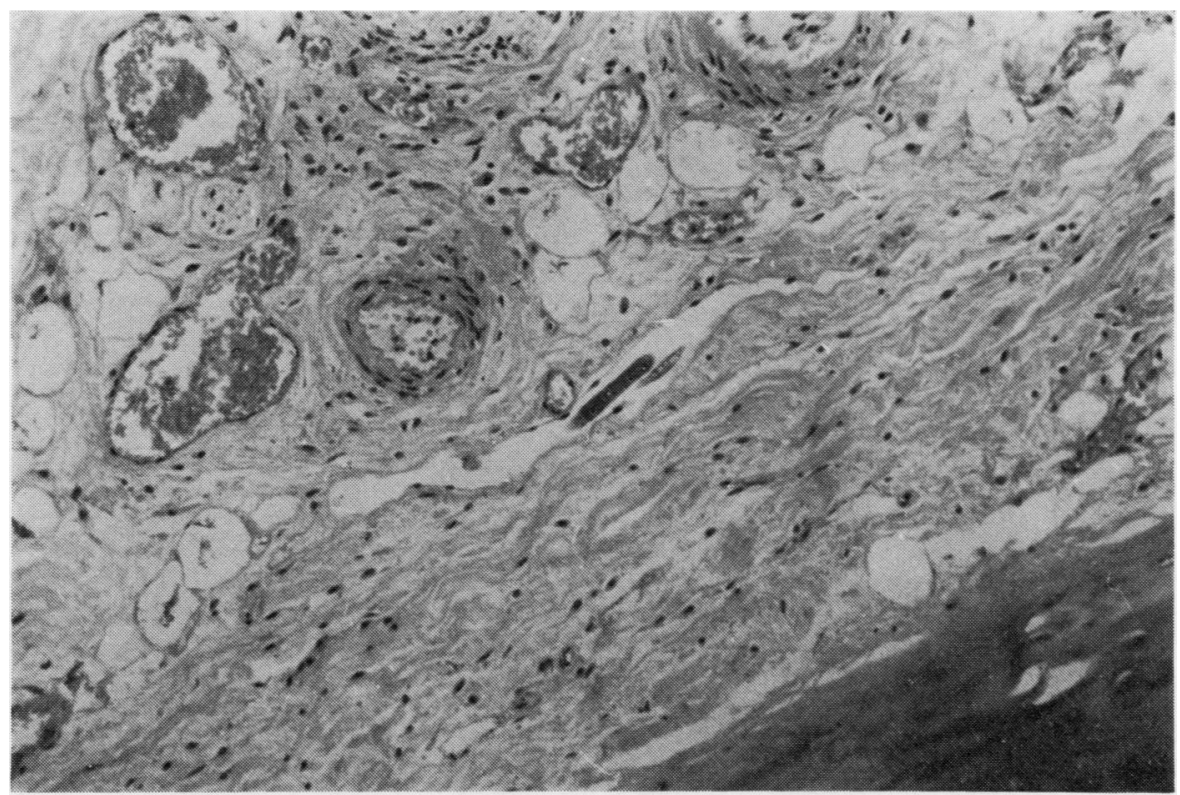

FIG. 2. Submucosa of medium-sized bronchus showing a larva of Strongyloides stercoralis lying in a lymphatic vessel (Haematoxylin and eosin $\times 150$ ).

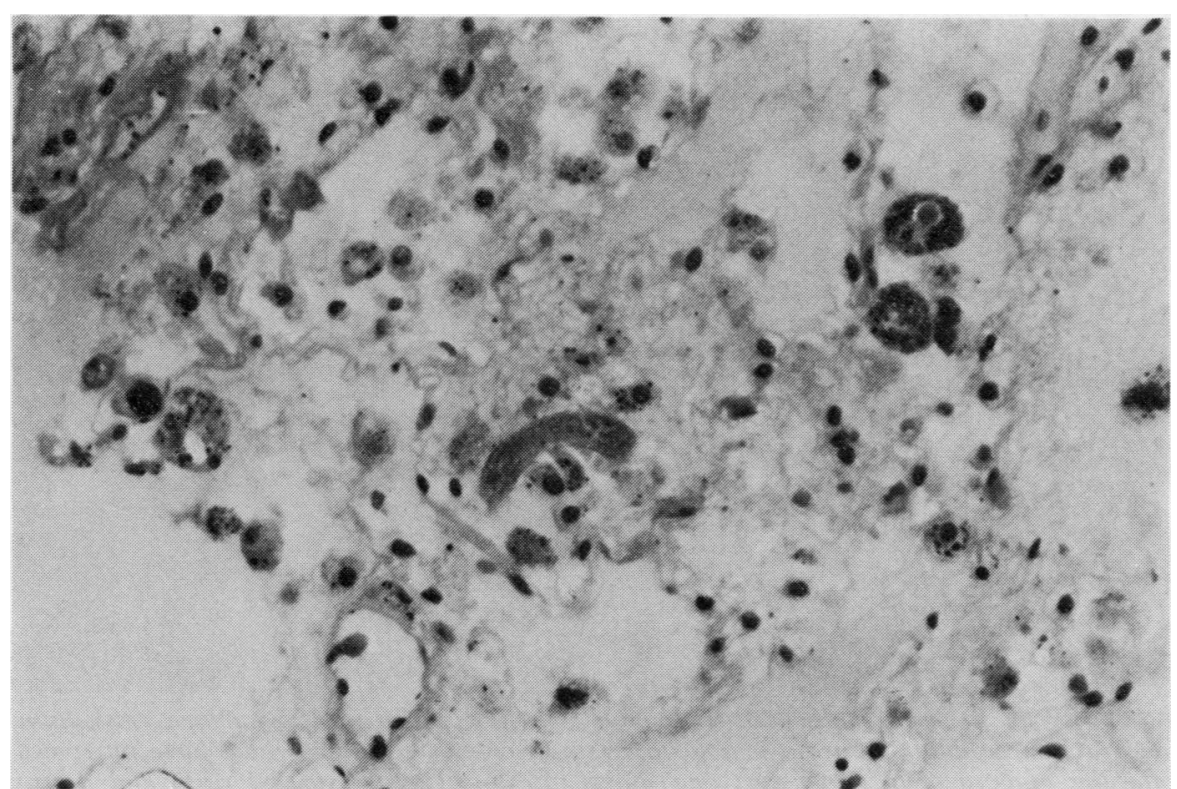

FIG. 3. Lung showing section of curved larva of Strongyloides stercoralis lying in two alveoli, in centre of photograph. Alveoli also contain oedema fluid, red cells, and dustladen histiocytes ( $H$ and $E \times 300$ ). 


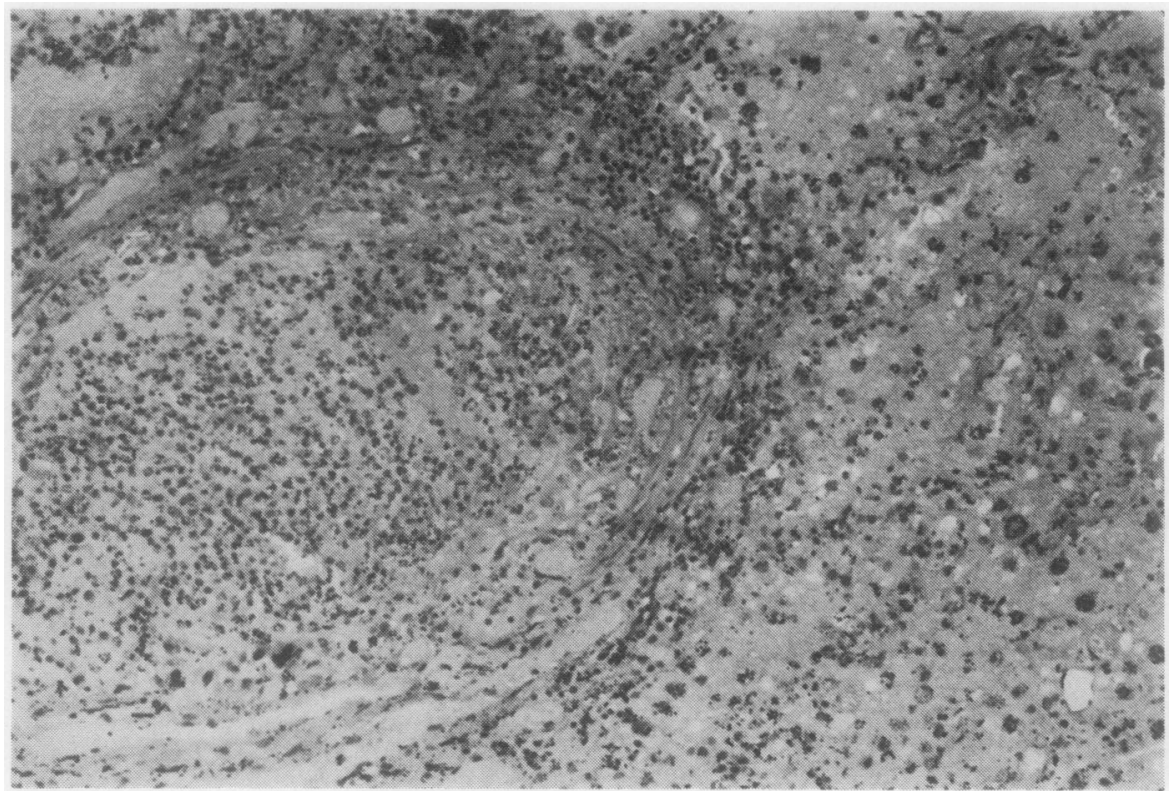

FIG. 4. Low-power view of lung section showing an inflamed non-respiratory bronchiole with many neutrophils in the lumen and a band of chronic inflammatory cells in the outer part of the wall. Some postmortem autolysis has taken place $(H$ and $E \times 130)$.

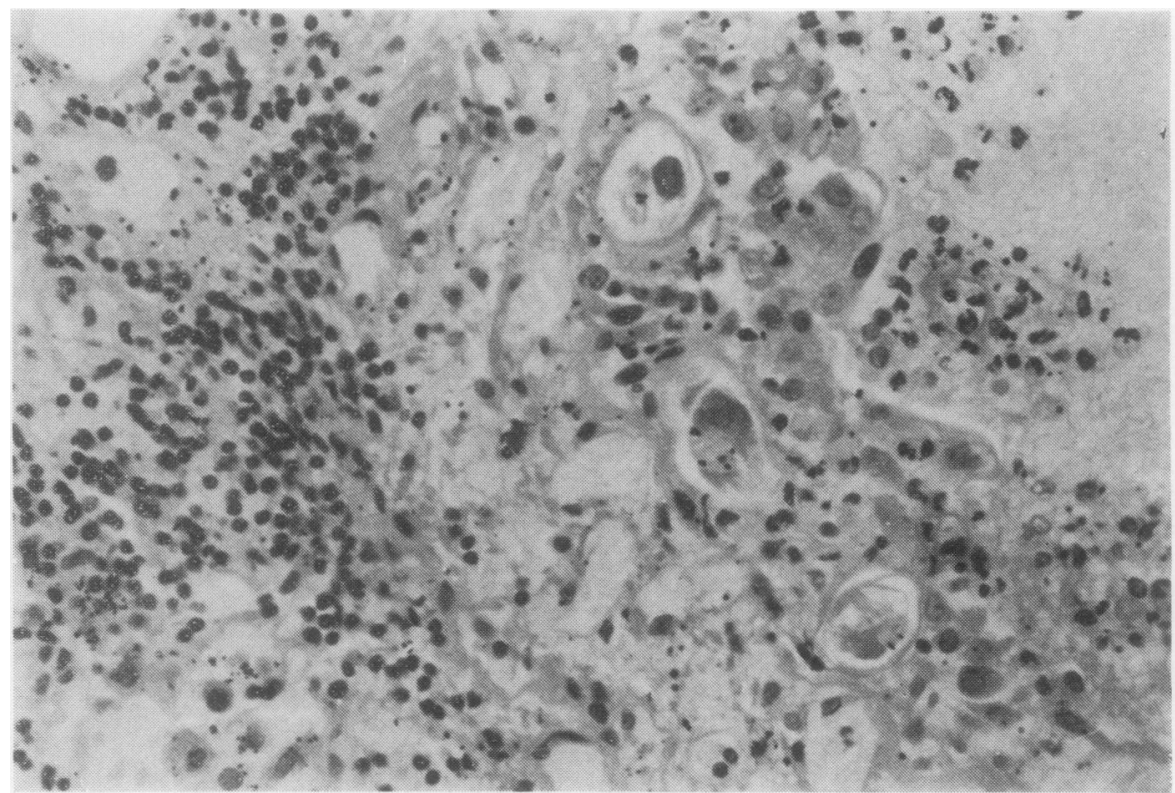

FIG. 5. Wall of bronchiole with lumen on right. Just beneath the surface epithelium there are three adult parasitic females of Strongyloides stercoralis which have burrowed into the mucosa. The uppermost one shows intestine (lightly stained ring) and uterus (darkly stained body). The very small dark dots on the parasites are mostly formalin pigment. On the left, there is a band of chronic inflammatory cells in the outer part of the bronchiolar wall $(H$ and $E \times 400)$. 


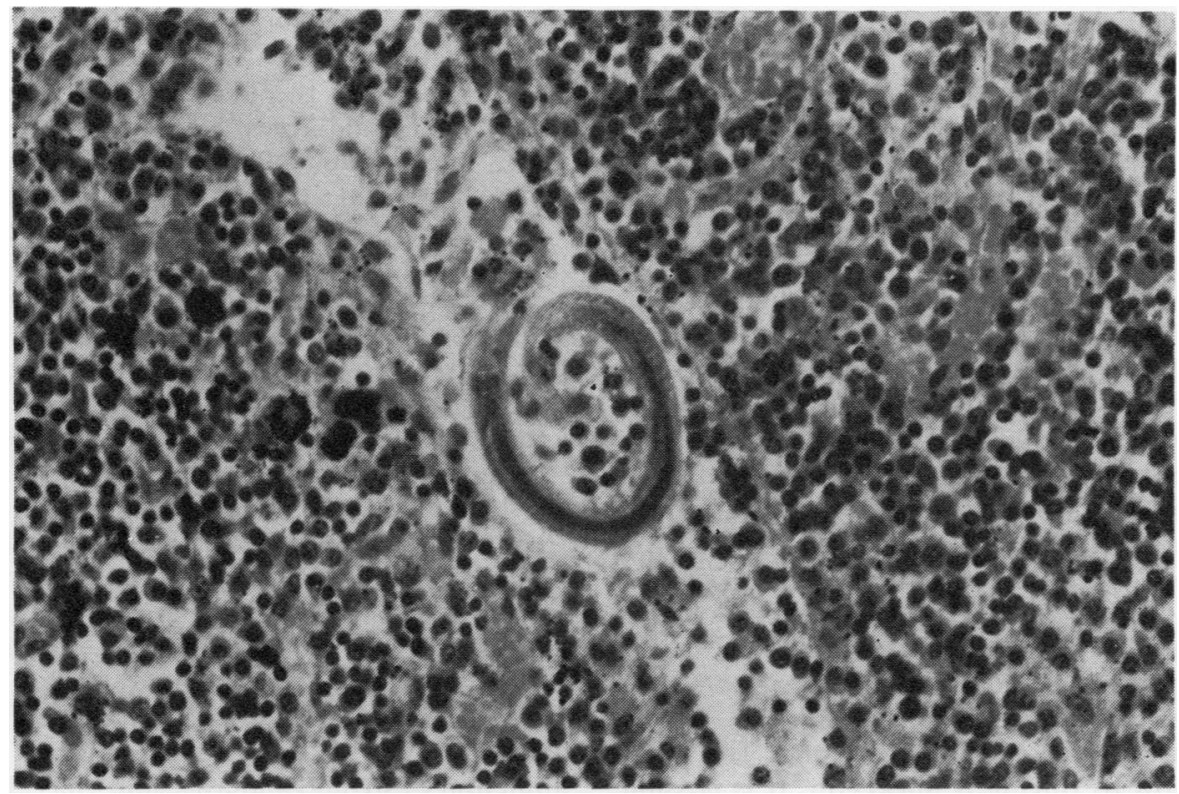

FIG. 6. Lymph node from a pulmonary hilus showing a larva of Strongyloides stercoralis in partial longitudinal section lying in a sinus. The head curves down into the centre from the right and there is a long oesophagus, suggesting that it is a filariform rather than a rhabditiform larva $(H$ and $E \times 330)$.

duodenum and jejunum. This probability is supported by the occurrence of a diarrhoeal illness shortly before death.

A small number of asbestos bodies were found on prolonged searching of $30 \mu$ thick sections of the lungs, suggesting mild exposure to asbestos dust, and probably explaining the pleural plaques. However, there was no evidence of pulmonary fibrosis of a type attributable to asbestos. Mild centrilobular emphysema was confirmed.

Histological sections of the spleen, liver, kidney, and adrenal showed no significant abnormality, and parasites were absent. There was no evidence of granulomatous hepatitis, as reported by Poltera and Katsimbura (1974).

\section{DISCUSSION}

The present case illustrates that a chronic infection with $S$. stercoralis originally acquired abroad may subsequently become transformed into a fatal overwhelming opportunistic pulmonary infection in a non-endemic area by the administration of corticosteroids. The diagnosis may be difficult because when strongyloidiasis is confined to the bowel it may sometimes cause no symptoms if the infection is minimal and the host's resistance is strong (Marcial-Rojas, 1971). A history of a single visit to an area where the worm is endemic may be the sole clue to the nature of potentially lethal complications years later. Long symptom-free intervals have been reported preceding intestinal symptoms (Cookson et al., 1972) and also generalized infections (Wilson and Thompson, 1964).

Sometimes overwhelming infections occur apparently without a predisposing cause (Brown and Perna, 1958; Bras et a!., 1964; Wilson and Thompson, 1964), but most oiten they appear as opportunistic infections in patients with advanced renal disease, or a malignant lymphoma, especially after treatment with corticosteroids (Cruz Reboucas, and Rochas, 1966; Rogers and Nelson, 1966; Willis and Nwokolo, 1966; Rivera et al., 1970; Fagundes, Basuto, and Brentano, 1971), or with immunosuppression.

Pulmonary symptoms range from an irritative cough to those of pneumonia, and may occur early on in the disease when larvae that have penetrated the skin migrate through the lungs before settling in the intestines. Airways obstruction has been noted by some workers (Corrigan, 1949; Ujda, 1972; Nwokolo and Imohiosen, 1973), and a rapid clinical response has been found with anthelminthic therapy. Nwokolo and Imohiosen 
(1973) found ova and a vegetative form of larva in the sputum of one patient, indicating that the adult female was probably present in the bronchial mucosa as a result of interruption of the normal migratory cycle (Mackie, 1948). It has been suggested that pulmonary haemorrhage and exudation occurring at the time of the initial migration may interfere with the ascent of larvae out of the lungs via the trachea. In asthmatics, bronchial mucous plugs may have a similar effect. In ordinary circumstances, the vegetative rhabditiform type of larvae of S. stercoralis are produced in the crypts of the duodenal and jejunal mucosae and pass out in the faeces in that form; they transform into the infective filariform type of larvae only outside the body. Sometimes, however, filariform larvae form within the bowel lumen (Craig et al., 1970) and invade the wall by 'internal autoinfection' to cause further episodes of pulmonary migration, consequently increasing the chances of a persistent bronchial infection with $S$. strongyloides.

The reason why the asthma dated from our patient's visit to Burma is uncertain. It is possible that it was caused by the presence of the parasite in the bowel, but in view of the normal level of IgE in the serum, and the absence of a cross reaction with filarial antibody together with absence of atopy, it is thought more likely to have been a coincidental onset of an intrinsic type of asthma. Histology at necropsy indicated that the worsening of symptoms and eventual fatal outcome were associated with the presence of adult worms as well as larvae in the lung, resulting in what is best termed a 'parasite bronchitis', aggravating the asthma.

The prevalence in Britain of airways obstruction due to $S$. stercoralis must be very low, but, judging from present experience, cautiousness in giving corticosteroids to asthmatics who have lived or travelled in endemic areas seems to be necessary. Pulmonary strongyloidiasis should be suspected always in such people if their airways obstruction fails to respond to steroids, as in the present case. In view of the facility with which people can travel abroad nowadays, a case could be made for scanning the stools of all such asthmatics for parasites before starting corticosteroid therapy.

The clinical diagnosis of strongyloidiasis may be difficult if the infestation is only moderate; ova or larvae need to be identified in concentrated stool. Duodenal aspiration with microscopy is not considered rewarding diagnostically (Kanani and Rees, 1970), but jejunal biopsy and the finding of $S$. stercoralis in the mucosa has been used successfully (Willis and Nwokolo, 1966). Additional help in diagnosis has been obtained from the reported $\overrightarrow{\vec{s}}$ cross reactivity of sera from patients with strongy- $\overline{0}$ loidiasis alone in the filarial complement fixation $\frac{C}{\partial}$ test (Kanani and Rees, 1970). With heavy infec- $\overline{\bar{c}}$ tions, the ova and larvae may be found success- $\overparen{\Phi}$ fully in sputum, urine, and concentrated stool. The parasite has also been reported in the pleural ${ }^{\infty}$ fluid in some cases (Fróes, 1930). The presence of $\vec{O}$ a raised eosinophil count is not necessarily helpful, $\overrightarrow{\vec{\omega}}$ except to heighten one's suspicion, as it may re- $\omega$ flect other disease processes and is occasionally $\overrightarrow{\vec{x}}$ absent in severe strongyloidiasis (Bras et al., 1964), $\stackrel{x}{\dot{\omega}}$ and in any case steroids suppress the eosinophils.

Needless to say, if an infection with $S$. stercor- iv alis is demonstrated in an asthmatic, it should be $N$ treated radically before corticosteroid therapy. $\mathrm{O}$ Similarly, if it is discovered in an asthmatic unre- $\stackrel{\supset}{-}$ sponsive to steroids, the dosage should be re- $\rightarrow$ duced, if possible, and energetic anthelminthic therapy instituted. There is a choice of agents available for treatment of $S$. stercoralis infections. Thiabendazole is successful in most cases of $\%$ alimentary strongyloidiasis and has been used effectively also in massive strongyloidiasis with pneumonia (Cahill, 1967). However, it was not successful in one patient with pulmonary infection who had received corticosteroid therapy (Cahill, $\stackrel{\unrhd}{\unrhd}$ 1967). In the case of asthma and strongyloidiasis $\overrightarrow{\vec{A}}$ diethylcarbamazine has been reported as more 3 effective than thiabendazole (Nwokolo and Imohiosen, 1973). Newer anthelminthic agents, such: as levamisole, are at present under trial (Adam et al., 1973) and may prove more effective in the을 future.

We are indebted to Dr. L. Capel, of the London Chest Hospital, for permission to publish this case, and also to Professor G. S. Nelson, of the London School of Hygiene and Tropical Medicine, and Professor H.오 Spencer, of St. Thomas' Hospital Medical School, for $>$ advice on the helminthology. Figure 1 was prepared을. by the Department of Medical Photography, Chester Beatty Research Institute.

\section{REFERENCES}

Adam, M., Morgan, O., Persaud, C., and Gibbs, W. N. (1973). Hyperinfection syndrome with Strongy-市 loides stercoralis infection in malignant? lymphoma. British Medical Journal, 1, 264.

Andrade, Z. A. and Gomes, M. C. (1964). Pathologyoof fatal strongyloidiasis. Revista do Instituto ded Medicina Tropical de São Paulo, 6, 28.

Bras, G., Richards, R. C., Irvine, R. A., and Milner,, P. F. A. (1964). Strongyloides stercoralis in Jamaica. Lancet, 2, 1257. 
Brown, H. W. and Perna, V. P. (1958). An overwhelming strongyloides infection. Journal of the American Medical Association, 168, 1648.

Cahill, K. M. (1967). Thiabendazole in massive strongyloidiasis. American Journal of Tropical Medicine and Hygiene, 16, 451.

Chodkowska, S., and Piekarniak, K. (1968). Infestation with Strongyloides stercoralis as a complica. tion of pulmonary diseases (Polish, with English summary). Gruźlica, 36, 29.

Cookson, J. B., Montgomery, R. D., Morgan, H. V., and Tudor, R. W. (1972). Fatal paralytic ileus due to strongyloidiasis. British Medical Journal, 4, 771.

Corrigan, F. L. (1949). A case of pulmonary strongyloidiasis. British Medical Journal, $2,738$.

Craig, E. C., Russell, P. F., and Jung, R. C., eds. (1970). Craig and Faust's Clinical Parasitology, 8th edition, chapter 20, p. 297. Lea and Febiger.

Cruz, T., Reboucas, G., and Rochas, H. (1966). Fatal strongyloidiasis in patients receiving corticosteroids. New England Journal of Medicine; 275, 1093.

Fagundes, L. A., Basuto, D., and Brentano, L. (1971). Strongyloidiasis: fatal complication of renal transplantation. (Letter.) Lancet, 2, 439.

Fróes, H. P. (1930). Identification of nematode larvae in the exudate of a sero-haemorrhagic pleural effusion. Journal of Tropical Medicine, 33, 18.

Heard, B. E. (1969). Pathology of Chronic Bronchitis and Emphysema, p. 10. Churchill, London.

Kanani, S. R. and Rees, P. H. (1970). The diagnosis of strongyloidiasis with special reference to the value of the filarial complement fixation test as a screening test. Transactions of the Royal Society of Tropical Medicine and Hygiene, 64, 246.

Mackie, T. T. (1948). Parasitic infections of the lung. Diseases of the Chest, 14, 894.
Marcial-Rojas, R. A. (1971). Strongyloidiasis. In Pathology of Protozoal and Helminthic Diseases, edited by R. A. Marcial-Rojas, p. 711. Williams and Wilkins, Baltimore. Churchill Livingstone, Edinburgh and London.

Nwokolo, C. and Imohiosen, E. A. E. (1973). Strongyloidiasis of the respiratory tract presenting as "asthma". British Medical Journal, 2, 153.

Poltera, A. A. and Katsimbura, N. (1974). Granulomatous hepatitis due to Strongyloides stercoralis. Journal of Pathology, 113, 241.

Rivera, E., Maldonado, N., Vélez-García, E., Grillo, A. J., and Malaret, G. (1970). Hyperinfection syndrome with Strongyloides stercoralis. Annals of Internal Medicine, 72, 199.

Rogers, W. A., Jr. and Nelson, B. (1966). Strongyloidiasis and malignant lymphoma. Journal of the American Medical Association, 195, 685.

Seabury, J. H., Abadie, S., and Savoy, F., Jr. (1971). Pulmonary strongyloidiasis with lung abscess. American Journal of Tropical Medicine and Hygiene, 20, 209.

Ujda, J. (1972). Case of bronchial asthma in the course of infestation with Strongyloides stercoralis. (Polish, with English summary.) Wiadomósci Lekarski, 25, 1089.

Willis, A. J. P. and Nwokolo, C. (1966). Steroid therapy and strongyloidiasis. Lancet, 1, 1396.

Wilson, S. and Thompson, A. E. (1964). A fatal case of strongyloidiasis. Journal of Pathology and Bacteriology, 87, 169.

Woźiewski, Z. (1968). Pulmonary tissue as a site of Strongyloides stercoralis infestation. (Polish, with English summary.) Gruźlica, 36, 35.

Requests for reprints to: Dr. T. W. Higenbottam, Respiratory Function Unit, Guy's Hospital, St. Thomas Street, London SE1 9RT. 